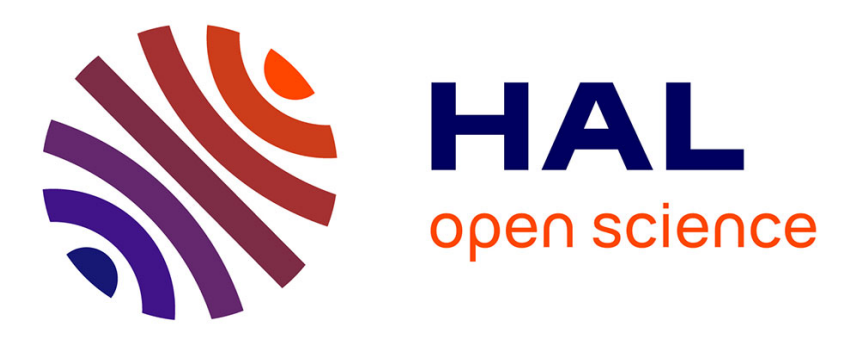

\title{
Glass transition in the spin density wave phase of (TMTSF)2PF6 investigated by calorimetric measurements
}

\author{
J. Lasjaunias, J. Odin, K. Biljakovic, P. Monceau, K. Bechgaard
}

\section{To cite this version:}

J. Lasjaunias, J. Odin, K. Biljakovic, P. Monceau, K. Bechgaard. Glass transition in the spin density wave phase of (TMTSF)2PF6 investigated by calorimetric measurements. Journal de Physique IV Proceedings, 1993, 03 (C2), pp.C2-365-C2-368. 10.1051/jp4:1993273 . jpa-00251356

\section{HAL Id: jpa-00251356 https://hal.science/jpa-00251356}

Submitted on 1 Jan 1993

HAL is a multi-disciplinary open access archive for the deposit and dissemination of scientific research documents, whether they are published or not. The documents may come from teaching and research institutions in France or abroad, or from public or private research centers.
L'archive ouverte pluridisciplinaire HAL, est destinée au dépôt et à la diffusion de documents scientifiques de niveau recherche, publiés ou non, émanant des établissements d'enseignement et de recherche français ou étrangers, des laboratoires publics ou privés. 


\title{
Glass transition in the spin density wave phase of $(\mathrm{TMTSF})_{2} \mathrm{PF}_{6}$ investigated by calorimetric measurements
}

\author{
J.C. LASJAUNIAS ${ }^{*}$, J. ODIN*, K. BILJAKOVIC ${ }^{* * *}$, P. MONCEAU* and K. BECHGAARD ${ }^{* * *}$ \\ * Centre de Recherches sur les Très Basses Températures, CNRS, Laboratoire associé à l'Université Joseph \\ Fourier, BP. 166, 38042 Grenoble cedex 9, France \\ ${ }^{* *}$ Institute of Physics of the University of Zagreb, P.O. Box 304, 41001 Zagreb, Croatia \\ ${ }^{* * *}$ Department of General and Organic Chemistry, H.C. Oersted Institute, 2100 Copenhagen, Denmark
}

\begin{abstract}
We report on detailed kinetic investigation of the specific heat anomaly of the spin density wave phase of (TMTSF) $2 \mathrm{PF}_{6}$ in the temperature range $2.5-5 \mathrm{~K}$. We point out the crucial role of kinetic conditions and of previous thermal history, such as isothermal annealing, which causes large hysteretic phenomena. This gives strong support to the origin of the anomaly in a glass transition which can be described in the general framework of freezing of supercooled liquids. For the unannealed system, $\mathrm{Tg}=3.45 \mathrm{~K}$.
\end{abstract}

The glassy behaviour of charge density wave (CDW) and spin density wave (SDW) systems has been established over a very wide temperature range and in very different energy-time windows [1-3]. In particular, low-T thermodynamical properties are characterized by two typical features : (i) additional excitations to regular phonons which contribute to the specific heat $C_{p}$ for $T$ below $0.5 \mathrm{~K}$ [4], reminiscent of low-energy excitations in glasses, and (ii) slow, non exponential heat relaxion, with "aging" effects [5] which are reminiscent of spin glasses behaviour in the vicinity of their freezing temperature. Very recently, dielectric measurements in $\mathrm{TaS}_{3}$ [6] and (TMTSF) $2 \mathrm{PF}_{6}$ [7] have shown a critical slowing down which, together with the slow heat relaxation dynamics below $1 \mathrm{~K}$, were taken as the indirect evidence of glass transition in the temperature range of crossover of these two relaxational processes. We have previously reported [8] a specific heat anomaly in the form of a jump in the lattice specific heat of (TMTSF) $2 \mathrm{PF}_{6}$ between 2.9 and $4 \mathrm{~K}$, in the same T-range where numerous anomalies occur, for example in N. M. R. [9] or non linear transport [10]. Here we present new specific heat data on (TMTSF) $2 \mathrm{PF}_{6}$ in order to clarify the origin of these anomalous behaviours.

Two different techniques were used:

(a) A quasiadiabatic (Q. A.) technique between 2.5 and $25 \mathrm{~K}$.

$408 \mathrm{mg}$ of sample in form of small needles was embedded in a silver epoxy resin and thereafter placed in the sample holder. After cooling down to the lowest temperature, the sample is isolated from the thermal bath and reheated adiabatically step by step. Each increase of $T$ (by about $3 \%$ ) is ensured by the heating process used to measure the heat capacity. Duration of heating is about $100 \mathrm{~s}$ and total data acquisition including the new thermal equilibrium is about 4-5 min. In the T-range of $3-5 \mathrm{~K}$, the heating rate is about $1.3 \mathrm{~K} / \mathrm{h}$.

(b) A transient heat pulse technique between 2 and $7 \mathrm{~K}$.

We used a similar arrangement as in our previous experiment [8]. Sample $(\mathrm{m}=110 \mathrm{mg})$ is loosely connected to the heat sink by a thermal link. Temperature of the sink is regulated step by step, either by cooling or heating, corresponding to relative variations of temperature of 3 to $5 \%$. Heating (or cooling) rate is about $0.5 \mathrm{~K} / \mathrm{h}$ between 2 and $4.5 \mathrm{~K}$ and duration of heat pulses is between 0.5 and $1 \mathrm{~s}$. Thermal transients in response to heat pulses are always exponential with time constant varying from $12 \mathrm{~s}$ at $\mathrm{T}=2 \mathrm{~K}$ to $80 \mathrm{~s}$ at $\mathrm{T}=5 \mathrm{~K}$.

In both techniques, heat capacity of addenda are determined by another experiment and then subtracted. Data obtained from different experimental conditions are compared in Fig 1:

(a) In the case of the quasiadiabatic technique (points $x$ ) specific heat obeys a $\beta \mathrm{T}^{3}$ law, with a slight variation of $\beta$ from 18.5 to $19.3 \mathrm{~mJ} / \mathrm{mol}$. $\mathrm{K}^{4}$ between 2.5 and $5.5 \mathrm{~K}$, without any 
discontinuity below $\mathrm{T}=4 \mathrm{~K}$. As shown in Fig. $2, \mathrm{C} / \mathrm{T}^{3}$ begins to decrease above $8 \mathrm{~K}$. At the SDW transition (TSDW $=12.1 \mathrm{~K}$ indicated by the arrow), $C \pi^{3}=15.5 \mathrm{~mJ} / \mathrm{mol}$. $\mathrm{K}^{4}$.

Other specific heat measurements by Coroneus et al. [11] with a pulse relaxation technique above $8 \mathrm{~K}$ give a lattice $\beta \mathrm{T}^{3}$ contribution between 8 and $12 \mathrm{~K}$, with $\beta=7 \mathrm{~mJ} / \mathrm{mol}$. $\mathrm{K}^{4}$.

(b) Data obtained with the transient heat pulse technique strongly depends on the thermal history of the sample, in the T-range from 2.5 to $4 \mathrm{~K}$. But an excellent agreement with the data of the adiabatic technique is recovered from $\mathrm{T}=7 \mathrm{~K}$ down to $4 \mathrm{~K}$ or even $3 \mathrm{~K}$, depending on the degree of annealing of the sample. Indeed, we report two series of data corresponding to extreme conditions of relaxation.

The lower branch (symbol $\Delta$ ) is obtained after a first cooling down to $T=1.9 \mathrm{~K}$, when data are regularly taken on reheating (or by cooling between 4.5 and $2.9 \mathrm{~K}$ ) at a rate of 0.5 $\mathrm{K} / \mathrm{h}$, without any intermediate stabilisation : it corresponds to the "unannealed" state. This branch exactly reproduces the anomaly previously measured in similar conditions [8] ; it shows a jump at $T=3.45 \mathrm{~K}$. The second series of data (symbols 0 and $\bullet$ ) shows an hysteretic behaviour for a "well-annealed" state, i. e. after the sample has been annealed at $\mathrm{T}_{\mathrm{a}}=2.77 \mathrm{~K}$ for $40 \mathrm{~h}$, following other previous isothermal annealing (or stabilisations).

All these phenomena which are in details explained in a separate paper [16], can be interpreted in the general framework of glass transition of supercooled liquids (S. L.) [12]. The jump in $\mathrm{C}_{\mathrm{p}}$ (here in $\mathrm{C} / \mathrm{T}^{3}$ because specific heat is mainly a lattice contribution following Debye law) indicates the freezing in of the configurational enthalpy measured over the experimental time span. Below $\mathrm{T}_{\mathrm{g}}$, there only remains the vibrational contribution of the glass (here described by the lattice term) $\mathrm{C}_{\mathrm{pg}}=\alpha \mathrm{T}^{3}$, with $\alpha=15 \mathrm{~mJ} / \mathrm{mol}$. $\mathrm{K}^{4}$. Above $\mathrm{T}_{\mathrm{g}}$, the equilibrium specific heat $C_{p e}=\beta T^{3}\left(\beta \approx 18.5 \mathrm{~mJ} / \mathrm{mol}^{\prime} \mathrm{K}^{4}\right)$ corresponds to the equilibrium value of the "S. L." , including both configurational and vibrational contributions. The apparent specific heat in the vicinity of $\mathrm{T}_{\mathrm{g}}$ is strongly dependent on the previous thermal history (such as isothermal annealing in our case) or in general on kinetic conditions (heating vs. cooling rates, energy delivery procedure).

A characterictic phenomenon related to the glass transition is the endothermic overshoot above $C_{p e}$ observed on reheating after a stabilisation at $T_{a}$. This is a purely kinetic effect (apparent specific heat) explained by the delayed recovery of relaxed enthalpy towards the equilibrium S. L. value [13-15], that we observed (points o in Fig 1) after a stabilisation at $\mathrm{T}_{\mathrm{a}}=2.77 \mathrm{~K}$. On subsequent cooling from $4.5 \mathrm{~K}$ (points $\bullet$ ), as the system is in a highly relaxed state it can longer follow the equilibrium value $C_{\text {pe }}$ down to $T=3$. OK, then it freezes in, but at a much lower temperature than the initial $\mathrm{T}_{\mathrm{g}}$ of the unannealed state. Along this cooling cycle, note the excellent agreement with data of the $Q$. A. technique. But we have also to emphasize the differences obtained with both techniques which correspond to very different kinetic conditions, such as the duration of the thermal excitation. In the $Q$. A. technique, energy is delivered in more than one minute and one waits for the new thermal equilibrium during several minutes more. In contrast, in the heat pulse technique thermal excitation is sent for less than one second, and the system returns to the initial equilibrium within several tens seconds. It appears that with the first procedure, all degrees of freedom of the configurational states can be excited within this time span (at least down to $2.5 \mathrm{~K}$ ), whereas this is possible only after long stabilisations with the second procedure. However, as $T$ increases, the internal mobility of configurational states increases and the two techniques give similar results above $4 \mathrm{~K}$.

The metastable nature of the glassy state around $T_{g}$ is confirmed by the systematic spontaneous increase of $C_{p}$ during each stabilisation between 2.5 and $3.5 \mathrm{~K}: \mathrm{C}_{\mathrm{p}}$ increases from the lower branch to reach $C_{p e}$, sometimes after the overshoot on reheating [16].

Now, we can estimate the variation of the equilibrium configurational enthalpy $\Delta H_{\sigma}$ for different fully relaxed states, compared to the value of the unannealed state. One has to define this variation from a reference temperature $T_{0}$ above $T_{g}$, where $C_{p}$ has recovered the equilibrium value. We take $T_{0}=4.5 \mathrm{~K}$. For the unannealed state, the variation of equilibrium enthalpy between $T_{g}$ and $T_{0}$ is :

$$
\Delta H_{\sigma 1}=H_{0}-H_{e}\left(T_{g}\right)=\int_{T}^{T_{0}}\left(C_{p e}-C_{p g}\right) d T=0.235 \mathrm{~J} . \text { mol}^{-1}, \quad \text { with } C_{p g}=\alpha T^{3}
$$




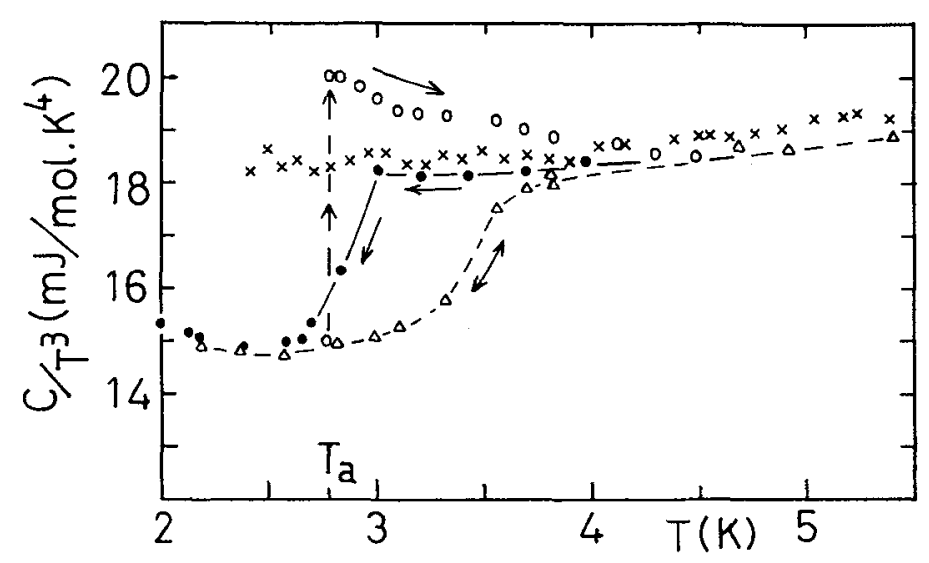

Fig. 1. Total specific heat of (TMTSF) $)_{2} \mathrm{PF}_{6}$ in a $\mathrm{C} / \mathrm{T}^{3}$ diagram obtained in very different kinetic conditions:

Data $(x)$ are obtained with the quasiadiabatic technique and correspond to the equilibrium state. Other data are obtained with the transient heat pulse technique : $(\Delta)$ correspond to regular heating or cooling (rate of $0.5 \mathrm{~K} / \mathrm{h}$ ) between 2.9 and $4.5 \mathrm{~K}$, for unannealed sample. $(0,0)$ show an hysteretic loop [0: for heating, $\bullet$ : for cooling] obtained after a stabilisation at $\mathrm{T}_{\mathrm{a}}$ $=2.77 \mathrm{~K}$ for $40 \mathrm{~h}$, which indicates a highly relaxed state.

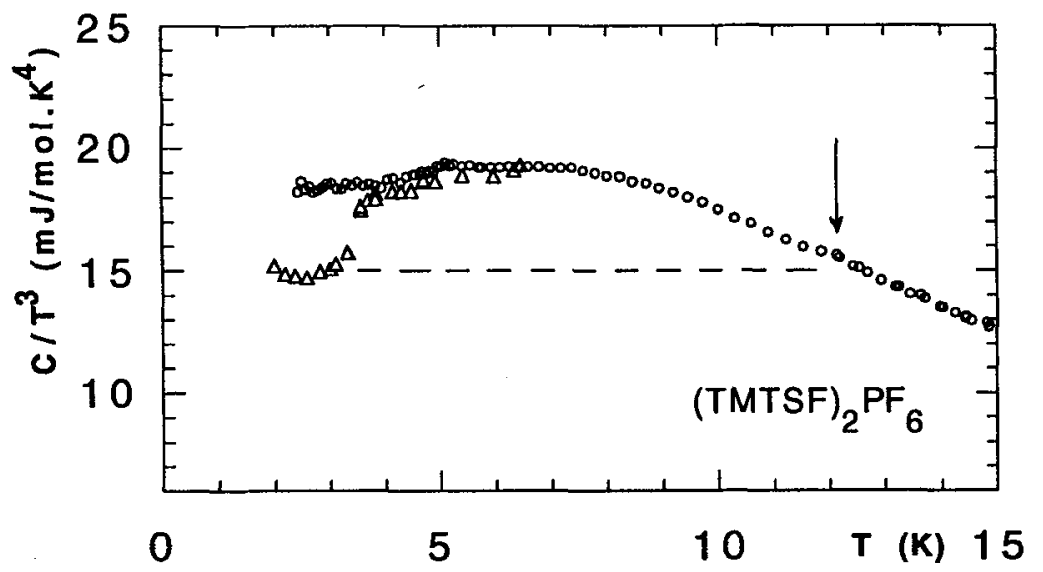

Fig. 2. Total specific heat of (TMTSF) ${ }_{2} \mathrm{PF}_{6}$ in $\mathrm{C} / \mathrm{T}^{3}$, between 2 and $15 \mathrm{~K}$. Data (o) are obtained with the quasiadiabatic technique; $(\Delta)$ with the transient technique, as in Fig. 1 . The straight line indicates the vibrational contribution of the "glass" measured below $3 \mathrm{~K}$ and extrapolated up to the SDW transition in order to estimate the configurational entropy in this T-range.

For different stabilisations (at $T_{a}=2.45,2.77$ and $2.92 \mathrm{~K}$ ) which let the sample to relax close to the equilibrium state, the variation $\Delta \mathrm{H}$ is obtained by integration from $\mathrm{T}_{\mathrm{a}}$ to $\mathrm{T}_{\mathrm{o}}$ of $\left(\mathrm{C}_{\mathrm{pa}}-\mathrm{C}_{\mathrm{pg}}\right)$, where $\mathrm{C}_{\mathrm{pa}}$ is the apparent (measured) specific heat. One obtains :

$\Delta \mathrm{H}_{\sigma}=\mathrm{H}_{\circ}-\mathrm{H}_{e}\left(\mathrm{~T}_{a}\right)=0.307,0.345$ and $0.375 \pm 0.015 \mathrm{~J}$. mol-1 for $\mathrm{T}_{a}=2.92,2.77$ and $2.45 \mathrm{~K}$, respectively. These values are very continuous and indicate variations of $\Delta \mathrm{H}_{\sigma}$ of the order of $10^{-4} \mathrm{~J}_{\mathrm{g}} \mathrm{g}^{-1}$, in comparison to those of the order of a few J. $\mathrm{g}^{-1}$ for similar relative variations of $T$ for typical structural glasses (polymer, metallic glasses...) [13-15] with $\mathrm{T}_{g} \sim 300$ $-400 \mathrm{~K}$

We have also estimated the configurational entropy $S_{\sigma}$ in the T-range between the SDW transition ( $T_{S D W}=12.1 \mathrm{~K}$ ) down to $T_{g}=3.45 \mathrm{~K}$, by extrapolating above $T_{g}$ the vibrational specific heat $\mathrm{C}_{\mathrm{pg}}=\alpha \mathrm{T}^{3}$ [see Fig.2]. This yields an underestimated value of 
$S_{\sigma}=1.52 \mathrm{~J} . \mathrm{mol}^{-1} \cdot \mathrm{K}^{-1}$, that we can compare to the much smaller entropy of the electronic condensate below $T_{\text {SDW }}: \gamma T_{\text {SDW }} \approx 0.25 \mathrm{~J}$. mol-1. $\mathrm{K}^{-1}[17]$. The difference may imply underlying electron-phonon interactions which are usually neglected in SDWs.

Using the general concepts established for glass-forming systems, we can test the classification between fragile and strong behaviour [18] in the case of this very particular SDW glass. This classification is based on the value $T_{g} / T_{0}$, where $T_{0}$ is the critical temperature obtained from the Vogel-Fulcher divergence of viscosity near $\mathrm{Tg}$. Here we obtain $\mathrm{T}_{0} \approx 2 \mathrm{~K}$ from low frequency - low $\mathrm{T}$ dielectric constant behaviour [7]. Depending on annealing conditions $1.25 \Sigma \mathrm{T}_{\mathrm{g}} / \mathrm{T}_{\mathrm{o}} \leqslant 1.8$, which corresponds to the fragile side of the classification. Accordingly, the specific heat jump at $\mathrm{T}_{\mathrm{g}}$ is observable.

Undoubtly we have shown the existence of a calorimetric glass transition in the SDW ground state of (TMTSF) ${ }_{2} \mathrm{PF}_{6}$ which certainly deserves a more wide and appropriate understanding of the underlying configurational changes.

\section{REFERENCES}

[1] Proceedings of the Int. Conf. on Science and Technology of Synthetic Metals, Göteborg, 1992, Synthetic Metals (1993) 56, part 1-2-3.

[2] LITTLEWOOD P.B. and RAMMAL R., Phys. Rev., B38, (1988) 1657.

[3] BILJAKOVIC' K., in Proceedings of "Phase transitions and relaxation in systems with competing energy scales", NATO adv. Inst., Geilo, Norway (1993).

[4] LASJAUNIAS J.C., BILJAKOVIC' K., and MONCEAU P., Physica B 165-166 (1990), 893 and Physica $A$, to appear.

[5] BILJAKOVIC' K., LASJAUNIAS J.C., MONCEAU P., and LEVY F., Phys. Rev. Lett. 67, (1991) 1902.

[6] NAD' F. and MONCEAU P., Solid State Commun., 87, (1993) 13.

[7] BILJAKOVIC' K., NAD' F., LASJAUNIAS J.C., MÓNCEAU P. and BECHGAARD K., submitted for publication.

[8] LASJAUNIAS J.C., BILJAKOVIC' K., MONCEAU P. and BECHGAARD K., Solid State Commun., 84, (1992) 297.

[9] TAKAHAŚHI T., Synth. Met. 27 (1988), B 397 ; WONG W. H., HANSON M.E., ALAVI B., CLARK W. G. and HINES W.A., Phys. Rev. Lett. 70 (1983), 1882.

[10] KRIZA G., QUIRION G., TRAETTEBERG O. and JEROME D., Europhys. Lett. 16 (1991), 585.

[11] CORONEUS.J., ALAVI B. and BROWN S. E., Phys. Rev. Lett. 70 (1993) 2332.

[12] See e. g. JONES G. O., "Glass", chap. 4, ed. Chapman and Hall (1971).

[13] CHEN H. S. and WANG T. T., J. Appl. Phys., 52 (1981) 5898.

[14] HARMELIN M. et al., J. Non Cryst. Solids, 74, (1985) 107.

[15] BOEHM L., INGRAM M. D. and ANGELL C. A., J. Non Cryst. Solids, 44, (1981).305.

[16] LASJAUNIAS J.C., BILJAKOVIC K. et al., submitted for publication.

[17] The mean field specific heat jump at the condensation temperature $\mathrm{T}_{\mathrm{sDw}}$ is $\Delta \mathrm{CP}=1.4 \gamma \mathrm{T}_{\mathrm{sDw}}$. We estimate the largest possible value $\gamma \sim 20 \mathrm{~mJ} / \mathrm{mol} . \mathrm{K}^{2}$ which gives the electronic entropy $\gamma T_{\mathrm{sDw}} \sim 250 \mathrm{~mJ} / \mathrm{mol}$. K.

[18] ANGELL C.A., J. Non Cryrst. Solids, 131 - 133 (1991), 13. 